\title{
FALSO CONHECIMENTO: POSSÍVEL ERRO DE VIÉS NA APRENDIZAGEM DE ESPANHOL POR BRASILEIROS
}

\begin{abstract}
RESUMO: A construção do conhecimento se iguala a qualquer construção física, cujas bases, se não sólidas e estáveis o suficiente, tendem a ruir. No processo de aprendizagem de um idioma estrangeiro, o desafio dos educadores tem sido contrabalancear essa oferta farta de informação que pode conduzir o cidadão a um desvio, uma facilidade que se mostra um erro de viés de disponibilidade, objetivo dessa pesquisa durante o processo de ensinoaprendizagem do Espanhol pela turma de 2015 do curso de Espanhol 1 do Centro de Línguas da UFG/CAJ. O método de investigação deu-se através de coleta de dados mediante entrevistas em sala de aula, observação e um questionário qualitativo dirigido aos alunos. A preconcepção de que o Espanhol se assemelha tanto ao Português se torna um obstáculo epistemológico que precisa ser visualizado e corrigido pelo educador. Os resultados preliminares mostram que esse erro de viés se multiplica com rapidez assustadora: ao apertar de um botão a máquina pode resolver esta ou aquela questão, ficando a falsa impressão de entendimento, de que se tem uma extensão de conhecimento ampla, mas que é na verdade externa e falsa, havendo a necessidade de compreensão desse erro e sua posterior correção por educadores e alunos.
\end{abstract}

Palavras-chave: falso conhecimento; aprendizagem de Espanhol; ferramentas de aprendizagem.

\section{FALSE KNOWLEDGE: POSSIBLE BIAS ERROR IN LEARNING OF SPANISH BY BRAZILIAN STUDENTS}

\begin{abstract}
The construction of knowledge is equal to any physical construction whose foundations, if not solid and stable enough, tend to crumble. In the learning process of a foreign language, the challenge of educators has been to offset this abundant supply of information that can lead citizens to a deviation, a facility that turns to be an availability bias error, aim of this research during the Spanish teaching-learning process for the class of Spanish I, in the Language Centre of UFG/CAJ during the first term of 2015. The method of investigation was through data collection by means of interviews in the classroom, observation and a qualitative questionnaire to students. The preconception that Spanish is very similar to Portuguese comes to be an epistemological obstacle that needs to be observed and modified by the teacher. Preliminary results show that this bias error multiplies itself with frightening speed: the machine can solve this or that issue in a click away, leaving the false impression of comprehension, the sensation that the one has a broader and deeper knowledge, but that's in reality an external and false truth; thus this error ought to be recognized by educators and students in order to provide its subsequent correction.
\end{abstract}

\footnotetext{
${ }^{1}$ Professora de Inglês e Espanhol do Ensino Médio e Cursos Livres de Idiomas. Professora de Inglês e Espanhol do Centro de Línguas da Universidade Federal de Goiás (UFG).
} 
Keywords: false knowledge; Spanish learning; learning tools.

\section{Introdução}

Desde o início de vida de todo ser humano, o processo de construção do conhecimento se dá através de diferentes formas, da comunicação, da observação e da linguagem, de empirismos, cognições e impressões que passam pela vida como imutáveis até se ter um contato maior com esta ou aquela força, com esta ou aquela verdade desnudada ou com a manipulação de algo que apenas se almejava como interesse distante e idealizado. A construção de um conhecimento, no caso a aprendizagem de um segundo idioma, tem se tornado um desafio aos educadores.

O fácil acesso à informação e uma parca seleção do que seria ou não apropriado àquele momento, conduzem o cidadão comum a um desvio, a uma facilidade que por vezes se mostra engodo. Opiniões ao invés de conhecimento, que se multiplicam com rapidez assustadora, e que saciam a curiosidade de milhares de usuários. Platão afirmava que a opinião (doxa) era o falso conhecimento. E que o conhecimento verdadeiro (episteme) depende do estudo profundo, de uma comprovação ordenada e uma posterior validação. Iglésias (2005) fala dessa situação onde o objeto transformador, ou seja, a intuição e o desejo do conhecimento através da pesquisa e estudo aprofundado são suprimidos em razão de um dispositivo superficial, de um viés disponibilizado pelo senso comum:

\footnotetext{
"Sendo a maioria das pessoas pouco exigente, as explicações dadas pelo mito, ou quaisquer outras explicações prontas de uma cultura, bastam para quebrar o espanto nascente, e, assim sendo, a filosofia não acontece. Aliás, é comum também que as questões mais fundamentais não cheguem a ser postas - um ser humano pode crescer, assimilando com naturalidade as explicações dadas pela sua cultura sobre o mundo que o circunda, quer se trate do mundo físico, quer do social. As regras de conduta, o sistema de organização social e muitas vezes não chegam a espantar ninguém. As pessoas crescem aceitando sem discutir os papeis sociais que lhes são atribuídos, sem jamais questionar seu valor e seu por que, como se tudo fosse parte da ordem natural e inevitável das coisas”. (IGLÉSIAS, 2005, p. 15)
}

"Conhece-te a ti mesmo e conhecerás os outros e o universo inteiro" (Inscrição no oráculo de Delfos, atribuída aos Sete Sábios - c. 650a.C.-550 a.C.), nesta afirmação mais conhecida através das palavras de Sócrates, delineamos algo que de tão simples parece impossível de se concretizar, mas que nada mais é do que a sugestão de que o verdadeiro conhecimento seja o autoconhecimento.

Russell (1940), filósofo britânico, trata desse realismo individual como "realismo ingênuo" e diz que: 
Todos começamos com o "realismo ingênuo", isto é, a doutrina de que as coisas são aquilo que parecem ser. Achamos que a grama é verde, que as pedras são duras e que a neve é fria. Mas a física nos assegura que o verdor da grama, a dureza das pedras e a frieza da neve não são o verdejar, a dureza e a frieza que conhecemos através de nossa experiência, e sim algo muito diferente. $\mathrm{O}$ observador, quando se lhe parece estar observando uma pedra, está na verdade, se devemos acreditar na física, observando os efeitos da pedra sobre si mesmo. (...) $\mathrm{O}$ realismo ingênuo conduz à física, e a física, se verdadeira, mostra que o realismo ingênuo é falso. Desse modo, o realismo ingênuo, se verdadeiro, é falso; portanto, ele é falso. ${ }^{1}$

Nesta passagem, observamos que o autor retrata um conhecimento de mundo que se antecipa ao de nós mesmos. Temos impressões que nos são inatas ou ofertadas antes de uma consciência própria a nos dirigir à introspecção, ao pensamento racional e lógico sobre nós mesmos. Conhecemos antes de autoconhecermos. E o ponto de partida do conhecimento exterior é uma faculdade que se encontra dentro de todo ser humano, embora nem todos saibam utilizá-la ou identifica-la bem: A intuição, classificada em três tipos, segundo Aranha e Martins (1993, p.54):

- A intuição sensível, aquela proveniente do conhecimento imediato oferecido pelos órgãos dos sentidos;

- A intuição inventiva, proveniente dos sábios, dos cientistas ou dos artistas, durante um processo investigativo ou de criação;

- A intuição intelectual, gerada através do esforço para apreender diretamente a essência de um objeto, e que possibilita a diferenciação entre os sentidos primários, que classifica e dirige a intuição sensível a um nível distinto, fino e caracterizado.

A partir da intuição, adquire-se um poder inventivo, conhecedor e investigativo, pois não se obedece a fatores externos cegamente, mas se tem uma força propulsora interna reveladora e incansável de obter o conhecimento além da superfície, da razão cega e paralisadora, acatadora do senso comum. Precisamos ousar; ir além de qualquer fronteira, levar nossa intuição a uma viagem eterna de conhecimento em que a capacidade de análise cresça à medida que alteramos nossa perspectiva do que seja verdadeiro e falso no mundo no

\footnotetext{
${ }^{1}$ RUSSELL, Bertrand. An inquiry into meaning and truth. Oxford, Routledge, 1940, p.15, tradução nossa. ("We all start from 'naive realism', i.e., the doctrine that things are what they seem. We think that grass is green, that stones are hard, that snow is cold. But physics assures us that greenness of grass, hardness of stone, and coldness of snow are not the greenness, hardness, and coldness that we know in our own experience, but something very different. The observer, when he seems to himself to be observing a stone, is really, if physics is to be believed, observing the effects of the stone upon himself.(...) Naive realism leads to physics, and physics, if true, shows that naive realism is false. Therefore naive realism, if true, is false; therefore it is false.").
} 


\title{
Atin revista Eletrônica da Pös-Graduação

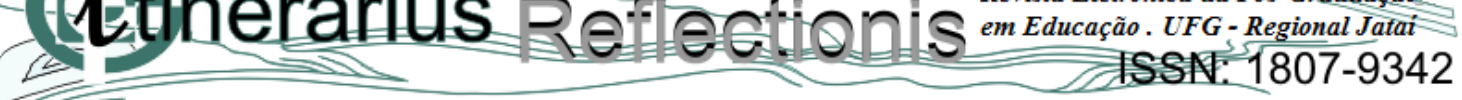 v. 11, n. 2,2015
}

qual nos relacionamos, e vice-versa. Toma-se o conhecimento muito somente através da experiência, das impressões que os objetos e os sujeitos do mundo externo nos fornecem e que recebemos através dos sentidos. O objetivo dessa pesquisa é tentar identificar o desvio nesse caminho do conhecimento no que tange a aprendizagem de uma língua estrangeira, no caso o Espanhol, idioma tido por muitos brasileiros como muito similar ao Português, o que cria um preceito errôneo na maioria dos estudantes que imaginam conhecer o que na realidade é mais complexo e que com o olhar correto e mais aprofundado se mostra matéria intrínseca; com seus paradigmas próprios, estruturas e vocabulário distintos e complexos que necessitam de tanta ou mais atenção, tempo e dedicação ao ser estudada e compreendida.

\subsection{Construção do conhecimento - falso conhecimento}

Nietzsche (1966), propôs uma inflexão sobre a temática do falso conhecimento:

\begin{abstract}
$O$ sancta simplicitiatas! Em qual estranha simplificação e falsificação vive o homem! Nunca se pode deixar de imaginar quando uma vez que se tenha olhos para contemplar essa maravilha! Como temos feito tudo ao nosso redor claro e livre e fácil e simples! Como temos sido capazes de dar aos nossos sentidos um passaporte para tudo que é superficial, nossos pensamentos um desejo divino para brincadeiras devassas e inferências erradas! (...) E só nesta solidificada fundação granítica da ignorância poderia o conhecimento erigir-se até aqui, o desejo do conhecimento sobre a fundação de uma vontade muito mais poderosa, a vontade da ignorância, do incerto, do falso! Não como seu oposto, mas - como seu requinte! É de se esperar, de fato, que a linguagem, aqui como em outros lugares, não superará a estranheza, e continuará a falar de opostos onde há apenas graus e muitos refinamentos de gradação; é igualmente de se esperar que a Tartuferia encarnada da moral, que agora pertence à nossa invencível "carne e sangue", tornará as palavras ao contrário nas nossas bocas, dos mais exigentes. Aqui e ali nós a entendemos, e rimos da maneira em que precisamente o melhor conhecimento busca mais fortemente nos reter neste simplificado, completamente artificial, adequadamente imaginado, e adequadamente falsificado mundo: na maneira em que, quer ele deseje ou não, ele ama o erro, porque, como um ser vivente, ele ama a vida! ${ }^{2}$
\end{abstract}

\footnotetext{
${ }^{2}$ NIETZSCHE, Friedrich. Beyond good and evil. Prelude to a philosophy of the future. Vintage Books Edition, 1966, p.35, tradução nossa. ("O sancta simplicitiatas! In what strange simplification and falsification man lives! One can never cease wondering when once one has got eyes for beholding this marvel! How we have made everything around us clear and free and easy and simple! how we have been able to give our senses a passport to everything superficial, our thoughts a godlike desire for wanton pranks and wrong inferences! (...) And only on this solidified, granite-like foundation of ignorance could knowledge rear itself hitherto, the will to knowledge on the foundation of a far more powerful will, the will to ignorance, to the uncertain, to the untrue! Not as its opposite, but - as its refinement! It is to be hoped, indeed, that language, here as elsewhere, will not get over its awkwardness, and that it will continue to talk of opposites where there are only degrees and many refinements of gradation; it is equally to be hoped that the incarnated Tartuffery of morals, which now belongs to our unconquerable "flesh and blood," will turn the words round in the mouths of us discerning ones. Here and there we understand it, and laugh at the way in which precisely the best knowledge seeks most to retain us in this simplified, thoroughly artificial, suitably imagined, and suitably falsified world: at the way in which, whether it will or not, it loves error, because, as living itself, it loves life!")
} 
Pois na busca pelo conhecimento, a probabilidade de erro e acerto seria de forma parcialmente idêntica, na aprendizagem de uma língua estrangeira como o Espanhol para os nativos em Português, essa probabilidade mostra-se desigual, pendendo a balança para o lado negativo quando quer que esse olhar de aceitação do já imaginado, simplificado e adquirido anteriormente na superficialidade de que seriam os dois idiomas como uma extensão similar de uma mesma linguagem.

O acesso indiscriminado e a facilitação que os veículos atuais de disseminação da informação transformam a ciência do aprendizado em uma caça ao invés de uma pesquisa que se baseie na razão inquisitiva, ou seja, na faculdade de raciocinar de maneira discursiva, de combinar conscientemente os conceitos e proposições; e as estratégias de pesquisa e formação do conhecimento para o estudante brasileiro de Espanhol acompanha passo a passo esse caminho perigoso de forma que, para o professor de Espanhol no Brasil, uma tática de ataque inicial, que parta para as diferenças e dificuldades do idioma, funciona, segundo resultados preliminares, como um dispositivo propulsor para um interesse focado no real aprendizado, sem desvios ou atalhos que impedem uma aprendizagem correta e posterior desejo de aprimoramento, utilizando da razão e da capacidade de julgamento individual, deixando de lado o senso comum. Segundo Lalande (1993 p.53) para Descartes, a razão é a faculdade de "bem julgar", ou seja, de discernir o bem do mal, o verdadeiro do falso. Conhecimento natural enquanto oposto ao conhecimento revelado, objeto da fé. Sistema de princípios a priori cuja verdade não depende da experiência individual.

\section{Objetivos}

O foco desta pesquisa dirige-se em especial ao falso conhecimento pelo que o uso frequente e por vezes indiscriminado de fontes como a Internet e a ideia inicial que o estudante tem como senso comum na aprendizagem de um segundo idioma, em especial o Espanhol - no que ele tem de similaridade em relação ao Português - torna difícil a distinção entre o que é real conhecimento e o que é errôneo e artificial.

$\mathrm{O}$ que o indivíduo possui realmente de seu no que tange a esse conhecimento - que conduz ao aprimoramento - e o que é externo, embora tão facilmente acessível a ponto de conferir essa ideia errônea e estranha de que ele é interno, que é parte do indivíduo? O indivíduo necessita desse olhar inteirado das peculiaridades e distinções, como afirma Veiga- 
v. 11, n. 2, 2015 ISSN: 1807-9342

Neto (2002, p. 30) “(...) é o olhar que botamos sobre as coisas que de certa maneira, as constitui. São os olhares que colocamos sobre as coisas que criam os problemas do mundo.”.

Veiga-Neto utiliza desse termo: olhar, para simbolizar a forma como o indivíduo encontra de encarar o desconhecido, os desafios e as probabilidades, bastando um olhar mais aprofundado e assertivo para ter uma resposta mais real, mais positiva e produtiva. $\mathrm{O}$ olhar passa a ser o diferencial, que decide se a busca é mais ou menos longa e penosa, se é velha ou nova, simples ou audaciosa. A realidade apresenta-se em uma infinidade de coisas e formas diferentes, e o olhar voltado a elas garante a multiplicidade da realidade que nos cerca. Contudo o olhar não contém o imo da realidade, ele apenas a revela para ser apreendida e as primeiras impressões são perigosas, deve-se fugir das primeiras aparências, do disponível ao primeiro contato, das utopias que adviriam dessa aceitação do superficial, o que não conduziria efetivamente ao conhecimento real.

Esse erro de viés de disponibilidade conduz a essa falta de observação e reflexão mais aprofundada, conduzindo por sua vez a essa falsa sensação de propriedade, está à mão, mas não na mente ou no coração.

Estando em sala de aula durante uma aula de Espanhol, em uma análise inicial foi possível perceber uma apatia e desinteresse pelo primeiro contato com o idioma, que permanecia no imaginário dos alunos como apenas um idioma muito parecido com seu próprio, "não digno" de uma imersão individual audaciosa e minuciosa. Foi-lhes oferecido um rol de palavras que até então não tinham conhecimento e que somado à utilização idiossincrática tornou-se objeto de interesse, porém sem ainda um entendimento profundo de que deveriam ser assimiladas e estudadas com mais cautela no ambiente fora de sala de aula. Essa oferta inicial de um vocabulário razoável que saliente as diferenças mescladas a algo de lúdico e interessante na construção do conhecimento desse idioma tornou o ambiente de sala de aula em um retorno ao ensino fundamental, o que de fato facilita esse contato com o idioma, pois é como se inseríssemos o aluno no ambiente que the ofertou o ensino aprofundado na língua materna. Aquele erro primário de disponibilidade foi desfazendo-se pouco a pouco com a compreensão ampliada de que o idioma Espanhol compõe-se de meandros e peculiaridades múltiplas e que é possível perceber sanar os erros com uma compreensão inicial das diferenças ao invés das similaridades - o que garantia essa confiança inicial errônea de que a semelhança com o Português conferia ao idioma Espanhol uma casualidade e desatenção involuntária no aprender. 
O conhecimento básico passa de externo para "propriedade" adquirida do aluno, corrigindo-se o erro de viés de disponibilidade, fenômeno que deixa no aluno a impressão de que sabe o que não sabe de verdade, embora pense e acredite que é dono desse saber, por encontrar no mais fácil, no que está à mão ou à mente o caminho para alcançar a solução de seu problema ou o conhecimento desejado. Para ser concreto e se ordenar, o saber tem que se cercar de estruturas que o aluno deve possuir, porém o educador deve ajudar a erigir. Foucault (2005, p.88) diz sobre o saber: “(...) ele (o saber) se ordena em torno da norma, em termos do que é normal ou não, correto ou não, do que se deve ou não fazer". O falso conhecimento aqui visto ficou claro na totalidade dos alunos avaliados e reconhecido por eles próprios durante os momentos em sala de aula. $\mathrm{O}$ aumento no interesse e no conhecimento real foi visível durante esse período, o Espanhol foi descrito por eles como "interessante", "difícil" e "desafiador". Houve o aumento também no interesse em se escutar o falar verdadeiro, os sotaques castelhanos reais, para deixar de lado o "portunhol" a que estavam acostumados a tomar como verdadeiro pronunciar do idioma Espanhol.

\section{Metodologia}

O método de investigação deu-se através de coleta de dados mediante entrevistas em sala de aula, observação durante as aulas e um questionário qualitativo dirigido aos alunos da turma de 2015 do curso de Espanhol 1 do Centro de Línguas da UFG/CAJ. O Centro de Línguas é um projeto de extensão da UFG, no qual a população tem acesso ao ensino de idiomas a um custo acessível, o curso é semestral, ministrado em diferentes níveis. A pesquisa-ação realizada no Centro de Línguas visa aprimorar a prática docente assim como a aprendizagem dos alunos, e tem como escopo a contribuição constante para a ação pedagógica. Portanto, a pesquisa encontra-se voltada para o Centro, e é realizada com os alunos sobre alguma parte do processo de ensino e aprendizagem, de forma a conhecer melhor esse processo e melhorar a qualidade dos serviços prestados.

Segundo Koshy (2005): “o principal papel da pesquisa-ação é facilitar aos praticantes o estudo dos aspectos da prática"; e ele ainda diz: "Conduzir uma pesquisa-ação significa desenvolver o ato de conhecer através da observação, escuta, análise e questionamento e estar envolvido na construção do próprio conhecimento"3.

Nesta pesquisa participaram 10 alunos com idade entre 20 a 50 anos, universitários, doutorandos, profissionais liberais, em sua maioria com foco na participação de congressos e eventos nos quais há a necessidade de conhecimento do Espanhol. Apesar da diversidade e 
diferença de faixa etária, era a primeira vez que faziam um curso de Espanhol, e a expectativa era muito similar entre todos os alunos.

\section{Resultados e discussão}

Os resultados iniciais reforçam a ideia de que o Espanhol para o estudante brasileiro se encontra nessa zona de erro de viés de disponibilidade, onde o sujeito tem o falso sentido de que o objeto a ser estudado lhe é muito similar ao que já lhe é conhecido e daí não necessita advir tanto esforço e pesquisa, bastando por vezes mesclar ou adivinhar ou tentar a sorte no que lhe parece ser a construção desse novo idioma em seu discurso individual e social.

Foram usados codinomes ao citar os depoimentos dos alunos. Uma aluna, quando questionada sobre como via o fator de similaridade entre o Português e Espanhol, respondeu:

De forma positiva, porque os idiomas são parecidos, o que facilita a compreensão, principalmente no momento da leitura. Se acaso me deparo com uma palavra de significado desconhecido, às vezes arrisco a adivinhar". (Entrevista, Rebeca, junho/2015).

Os alunos do curso de Espanhol 1 do Centro de Línguas se mostraram dispostos a buscar por esse aprendizado mais profundo, em resposta à pergunta do questionário sobre o que seria o maior facilitador do aprendizado, o resultado foi na razão do menos relevante, o uso do tradutor online, passando por busca em sites de Internet, consulta no dicionário, leituras, atividades em sala de aula e exercícios em casa, o mais relevante.

Porém, se confidenciaram sem o tempo necessário para essa dedicação fora da sala de aula, ou seja, o aprendizado do idioma Espanhol posicionou-se em segundo plano no que tange as atividades de aprendizagem gerais do estudante, que busca atender suas necessidades de estudo, trabalho ou aprendizagem primárias - podendo ser essas uma especialização ou posteriores formações de graduação, ou as atenções à própria profissão ou formação profissional; ficando assim o aprendizado do idioma em posição inferior, não sendo essa uma posição denegridora ou de exclusão, pois foi relatada como uma atividade de grande importância, porém o que se reflete no dia a dia verdadeiro é uma dedicação raquítica e subdesenvolvida por conta do pouco tempo restante, sendo sempre posterior ao trabalho e aprofundamento de outras atividades que não as do aprendizado do idioma. Em 100\% das respostas ao questionário, o Espanhol foi considerado um idioma de grande importância,

\footnotetext{
${ }^{4}$ Minha tradução para: "The main role of action research is to facilitate practitioners to study aspects of practice".(...) " carrying out action research is all about developing the act of knowing through observation, listening, analysing, questioning and being involved in constructing one's own knowledge.".
} 
como relatou a maioria dos alunos ao serem questionados sobre o que os levou a frequentar o curso de Espanhol:
A importância da língua. (Hector, questionário);
$\mathrm{O}$ interesse por aprender o idioma que me atrai muito, pois penso em tirar o passaporte e conhecer a Espanha. (Brendon, questionário);
O desejo de aprender Espanhol, acho importante conhecer outros idiomas. (Alana, questionário).

Porém as semelhanças com o idioma Português foram relatadas como uma facilitação, facilitação essa que se mostrou superficial, pois foi apenas detectada na compreensão de textos e na leitura, quando no que tange à formação de ideia e à produção textual o estudante esbarrou sempre no entrave de não conhecer verdadeiramente o idioma, muitas vezes deixando os textos com um excesso de "portunhol", acreditando estar realizando uma produção textual fiel ao idioma Espanhol.

\begin{abstract}
Eu nunca estudei Espanhol na escola, mas minha namorada teve Espanhol durante seu ensino regular, e isso, mesmo tendo sido há algum tempo atrás, fez toda a diferença. Ela já tinha uma base e essa base a fez compreender e falar melhor até mesmo na questão do sotaque. A ideia inicial que eu tinha era de que se tratava de algo muito parecido com o Português, e ainda conservo essa ideia, o que dificulta na hora de escrever ou tentar ler em Espanhol. Penso muito em Português. (Andersen, entrevista, julho/2015).
\end{abstract}

As ferramentas de tradução online, embora um recurso amplamente utilizado, foram consideradas insatisfatórias por $90 \%$ dos estudantes e os relatos falam sobre a questão gramatical, onde o tradutor se mostra ineficiente e se não houver um prévio conhecimento do aluno, os resultados se tornam infrutíferos ou errôneos.

Não são satisfatórios. É melhor usar as gramáticas e os dicionários, os resultados são melhores. (Rebeca, questionário);

Uso bastante, porém nem sempre é eficiente, tornando-se confuso às vezes. (Hector, questionário).

A tradução online nem sempre está $100 \%$ correta, imagino que por algumas variações de gramática, vendo por outro lado como a "resolvência" de um problema no momento, prefiro muito mais estudar o idioma. (Brendon, questionário).

\title{
5. Considerações finais
}

Houve uma concordância geral de que o conhecimento oferecido sem comprovação necessita de um aprofundamento individual e os estudantes relataram buscar realizar essa comprovação através de pesquisa e estudo, porém durante as aulas esse conceito mostrou-se fiel apenas no papel do questionário, esbarrando novamente na dificuldade relativa a tempo e conciliação de outros compromissos com o estudo do idioma. Por se identificar mais com o 
idioma materno, o Espanhol sofreu um desgaste ainda maior nessa questão da dedicação individual do aluno, pois se encontrou em uma zona de conforto a qual não se conferiu verídica assim que se foi constatando a real dificuldade e características singulares do idioma. Desse modo o educador tem que estar muito atento ao que os estudantes afirmam ter conhecimento com certeza ou com apenas a sensação de que possuem ou captaram aquele conhecimento com estudo e compreensão. Um segundo olhar é sempre essencial, e o reforço constante de atividades extraclasse que instiguem o aluno a despender tempo e dedicação, como a criação de próprios textos, jogos e atividades de caráter investigativo ou em grupo, disputas que se finalizariam em sala de aula, ou seja, atividades que levem o estudante a uma dedicação ativa e constante, onde daí se especifique as diferenciações e se sane as dúvidas, pois somente com o caráter investigativo da aprendizagem se consegue obter dúvidas consistentes para que sejam eficientemente sanadas. Será dada continuidade a essa pesquisa no semestre subsequente de 2015 , onde uma base mais consciente e adequada ao aprendizado do Espanhol se faz necessária para um equilíbrio entre o tempo dedicado e o viés adequado ao aprendizado, que se mostrou eficiente na demonstração das diferenças e particularidades entre os dois idiomas - Português e Espanhol.

\section{REFERÊNCIAS BIBLIOGRÁFICAS}

ARANHA, M. L. de A. e MARTINS, M. H. P. Filosofando: introdução à filosofia. 2.ed. São Paulo: Moderna, 1993. p.54.

FOUCAULT, M. A verdade e as formas jurídicas. 3.ed. Rio de Janeiro: NAU, 2005. p.88.

IGLÉSIAS, M. Pré-Socráticos: físicos e sofistas. In: REZENDE, A. (Org). Curso de filosofia: para professores e alunos dos cursos de segundo grau e de graduação. 13. ed. Rio de Janeiro: Jorge Zahar, 2005, p. 19-50.

KOSHY, V. Action research for improving practice. A practical guide. London: Paul Chapman Publishing, 2005, p. XII, XIV.

LALANDE, A. Vocabulário técnico e crítico de filosofia. Tradução por Fátima Sá Correia et al. São Paulo: Martins Fontes, 1993. p. 53.

NIETZSCHE, F. Beyond good and evil. Prelude to a philosophy of the future. Vintage Books Edition, 1966. p.35.

RUSSELL, B. An inquiry into meaning and truth. Oxford, Routledge, 1940. p.15.

VEIGA-NETO, A. Olhares. In: COSTA, M. V. (Org.). Caminhos investigativos: novos olhares na pesquisa em educação. Rio de Janeiro: DP\&A, 2002. p. 23-38. 
DOI: 10.5216/rir.v11i2.37983

\section{Atin Revista Eletrônica da Pós-Graduação}

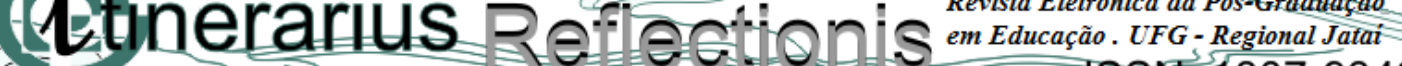

20

ISSN: 1807-9342

v. 11, n. 2,2015 